\title{
The Effects of ATIR Blocker on the Severity of COVID-19 in Hypertensive Inpatients and Virulence of SARS-CoV-2 in Hypertensive hACE2 Transgenic Mice
}

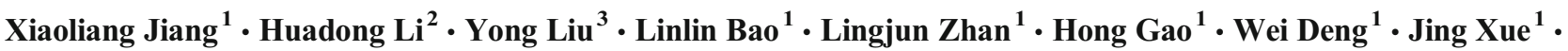 \\ Jiangning Liu ${ }^{1} \cdot$ Xing Liu ${ }^{1}$. Junli $\mathrm{Li}^{1}$ • Jie Wang ${ }^{1}$ - Shuang $\mathrm{Wu}^{2} \cdot$ Mingzhe Yan $^{2}$ - Wei Luo ${ }^{4}$ Pedro A. Jose ${ }^{5}$. \\ Chuan Qin ${ }^{1} \cdot$ Xiuhong Yang ${ }^{6} \cdot$ Dingyu Zhang $^{2} \cdot$ Zhiwei Yang $^{1}$ (i)
}

Received: 7 December 2020 / Accepted: 2 June 2021 / Published online: 1 January 2022

(C) The Author(s) 2021

\begin{abstract}
Angiotensin-converting enzyme 2 (ACE2) is required for the cellular entry of the severe acute respiratory syndrome coronavirus 2. ACE2, via the Ang-(1-7)-Mas-R axis, is part of the antihypertensive and cardioprotective effects of the renin-angiotensin system. We studied hospitalized COVID-19 patients with hypertension and hypertensive human(h) ACE2 transgenic mice to determine the outcome of COVID-19 with or without AT1 receptor (AT1R) blocker treatment. The severity of the illness and the levels of serum cardiac biomarkers (CK, CK-BM, cTnI), as well as the inflammation markers (IL-1, IL-6, CRP), were lesser in hypertensive COVID-19 patients treated with AT1R blockers than those treated with other antihypertensive drugs. Hypertensive hACE2 transgenic mice, pretreated with AT1R blocker, had increased ACE2 expression and SARS-CoV-2 in the kidney and heart, 1 day post-infection. We conclude that those hypertensive patients treated with AT1R blocker may be at higher risk for SARS-CoV-2 infection. However, AT1R blockers had no effect on the severity of the illness but instead may have protected COVID-19 patients from heart injury, via the ACE2-angiotensin1-7-Mas receptor axis.
\end{abstract}

Keywords Coronavirus disease 2019 · Hypertension · AT1 receptor blocker · Angiotensin converting enzyme 2

Xiaoliang Jiang, Huadong Li, Yong Liu, Linlin Bao and Lingjun Zhan contributed equally to this work.

Associate Editor Joost Sluijter oversaw the review of this article

Zhiwei Yang

yangzhiwei@cnilas.pumc.edu.cn

1 Key Laboratory of Human Disease Comparative Medicine Chinese Ministry of Health, Beijing Key Laboratory for Animal Models of Emerging and Remerging Infectious Diseases Institute of Laboratory Animal Science, Chinese Academy of Medical Sciences and Comparative Medicine Center, Peking Union Medical College, 5 Pan Jia Yuan Nan Li, Chaoyang District, Beijing 100021, People's Republic of China

2 Jinyintan Hospital, Wuhan, China, Dongxihu District, Wuhan 430023, People's Republic of China
Abbreviations

Ang1-7 Angiotensin 1-7

Ang Angiotensin 


$\begin{array}{ll}\text { ACE2 } & \text { Angiotensin-converting enzyme 2 } \\ \text { AT1R } & \text { AT1 receptor } \\ \text { cTnI } & \text { Cardiac troponin I } \\ \text { CFR } & \text { Case-fatality rate } \\ \text { COVID-19 } & \text { Coronavirus disease 2019 } \\ \text { CK-MB } & \text { Creatine kinase-myocardial band } \\ \text { hs-CRP } & \text { High-sensitivity C-reactive protein } \\ \text { IL-6 } & \text { Interleukin-6 } \\ \text { MasR } & \text { Mas receptor } \\ \text { RBD } & \text { Receptor-binding domains } \\ \text { RAS } & \text { Renin-angiotensin system } \\ \text { SARS-CoV-2 } & \begin{array}{l}\text { Severe acute respiratory syndrome } \\ \text { coronavirus 2 }\end{array}\end{array}$

\section{Introduction}

The coronavirus disease 2019 (COVID-19) pandemic caused by severe acute respiratory syndrome coronavirus 2 (SARSCoV-2) is a major public health problem. Cardiovascular diseases, including hypertension and diabetes, are the most common comorbidities that are associated with severe illness and high case-fatality rates (CFR) in COVID-19 [1, 2]. SARS$\mathrm{CoV}-2$ is a newly identified coronavirus with high genome similarity (89\%) and identity $(73 \%)$ of its receptor-binding domain (RBD) and similar ternary structure to SARS-CoV [3-5]. Molecular modeling revealed that SARS-CoV-2 RBD has a stronger interaction with angiotensin-converting enzyme 2 (ACE2), as cell entry receptor, than SARS-CoV [5]. ACE2 is a homologue of ACE but has physiological actions that oppose ACE [6]. ACE cleaves angiotensin I to generate angiotensin II which binds and stimulates the AT1 receptor (AT1R) to increase blood pressure, in part, via arterial constriction and renal sodium retention [7]. By contrast, ACE2 catalyzes the conversion of angiotensin (Ang) II into Ang1-7 which leads to vasodilatory, antiproliferative, and antiinflammatory effects via the Mas receptor. Thus, ACE2 counterbalances the effects of Ang II and exhibits antihypertensive and cardioprotective effects in humans and several rodent models [8].

AT1R blockers, such as losartan and olmesartan, are widely used in the therapy of hypertension. Urinary ACE2 levels are increased in hypertensive patients treated with the AT1R blocker (olmesartan), but not in patients treated with other AT1R blockers, such as losartan, candesartan, valsartan, and telminsartan [9]. However, losartan and other AT1R blockers have been reported to increase ACE2 expression in the kidney of spontaneously hypertensive rat and heart of mice or rat with cardiac hypertrophy and dysfunction caused by transverse aortic constriction or coronary artery ligation $[10,11]$. It has been suggested that angiotensin receptor 1 (AT1R) blockers may be used to reduce the cardiac damage in SARS-CoV-2 infection [12]. Retrospective studies found that hospitalized hypertensive patients with SARS-CoV-2 infection treated with ACE inhibitors or AT1R blockers have a lower risk of all-cause mortality than those treated with other drugs [13]. A prospective cohort study also found that ACE inhibitors and AT1R blockers are associated with a reduced progression of COVID-19 and do not increase the risk of intensive care [14]. However, due to ACE2 is critically important in the cellular entry of SARS and SARS-CoV-2, it is possible that hypertensive COVID-19 patients treated with drugs that increase ACE2, e.g., ACE inhibitors and AT1R blockers, are at a higher risk for the development and severity SARS-CoV-2 infection [15]. Indeed, hypertensive patients taking ACE inhibitors or AT1R blockers may have higher all-cause mortalities than those taking other drugs [16]. It has been suggested that ACE2-mediated inhibition of the AT1R pathway, which is beneficial in the treatment of hypertension, may also increase the susceptibility to pulmonary and cardiovascular disease in patients with COVID-19 [17]. Human (h) ACE2 transgenic mice, intranasally inoculated with SARS-CoV-2, develop severe pulmonary pathology with viral replication in the lungs and intestines, at 1-day post infection (dpi) and severe pulmonary pathology $5 \mathrm{dpi}$. There is no viral load in other organs [18]. The disease is more severe in aged mice [19], similar to that seen in humans [20]. The intranasal inoculation of SARS-CoV-2 in human (h) ACE2 transgenic mice results in $100 \%$ mortality within a few days [21]. However, the effect of AT1R blockers in hypertensive hACE2 transgenic mice, induced by angiotensin II and infected with SARS-CoV-2, has not been studied. Therefore, we studied hospitalized COVID-19 hypertensive patients and hypertensive hACE2 transgenic mice to determine whether AT1R blockers protect or promote the development of COVID-19 [17].

\section{Methods}

See the supplementary data for details.

\section{Results}

\section{AT1R Blockers May Protect Hypertensive COVID-19 Patients Against Inflammation and Heart Injury}

One-hundred forty-six hospitalized COVID-19 patients with hypertension were investigated, including 48 patients who took AT1R blockers for hypertension treatment (AT1RB group) and 98 patients who took other antihypertensive medications (Non-AT1RB group) before admission. After admission, all of them stopped taking all antihypertensive medications, including AT1R blockers, because of the concern that the latter such medications may worsen the outcome of 
SARS-CoV-2 infection. The age and sex distribution, and number of days of illness prior to admission, were similar in the two groups (Table 1). However, the severity of the disease, some symptoms, and some physical findings were lesser in the AT1RB than the non-AT1RB group, which could indicate that AT1R blockers may have reduced the severity of SARS-CoV-2 infection in these hypertensive patients, which was no dose-dependent effect.

We then compared the laboratory results on the admission of the two groups. The white blood cell and neutrophil counts, cardiac troponin levels, and interleukin-6(IL-6) levels were lesser in the AT1RB group than those in the non-AT1RB group (Fig. 1a). Therefore, we suggest that AT1R blockade may decrease the inflammation in hypertensive COVID-19 patients.

\section{Cardiac Function-Related Tests on Admission Are Strongly Associated with the Outcome in COVID-19 Inpatients with Hypertension}

In order to investigate the causes of death in all COVID-19 patients with hypertension, we analyzed the results of the laboratory tests on admission in survivors (103 patients) and nonsurvivors (43 patients) (Fig. 1b). We found that the admission

Table 1 Demographics and clinical characteristics on admission of hypertensive COVID-19 inpatients treated with AT1R blockers or non-AT1R blockers

\begin{tabular}{|c|c|c|c|}
\hline Variables & $\begin{array}{l}\text { AT1R blockers } \\
(\mathrm{n}=48)\end{array}$ & $\begin{array}{l}\text { Non-AT1R blockers } \\
(\mathrm{n}=98)\end{array}$ & $\mathrm{P}$ value \\
\hline Age (years) & $62.5(11.55)$ & $64.6(9.83)$ & 0.2472 \\
\hline Sex & & & 0.7246 \\
\hline Male, n (\%) & $23(47.9)$ & $50(51.0)$ & \\
\hline Female, n (\%) & $25(52.1)$ & $48(49.0)$ & \\
\hline BMI $\left(\mathrm{kg} / \mathrm{m}^{2}\right)$ & $26.2 \pm 3.1$ & $27.5 \pm 4.3$ & 0.265 \\
\hline \multicolumn{4}{|l|}{ Blood pressure } \\
\hline Systolic (mm Hg) & $137.4 \pm 17.7$ & $134.8 \pm 17.4$ & 0.2754 \\
\hline Diastolic (mm Hg) & $84.1 \pm 11.5$ & $82.7 \pm 10.8$ & 0.1889 \\
\hline Clinical severity & & & $0.0293 *$ \\
\hline Mild, n (\%) & $30(62.5)$ & $43(43.9)$ & \\
\hline Severe, n $(\%)$ & $15(31.3)$ & $42(42.9)$ & \\
\hline Critical, n (\%) & $3(6.3)$ & $13(13.3)$ & \\
\hline \multicolumn{4}{|l|}{ Medical history, n (\%) } \\
\hline Nephropathy & $1(2.1)$ & $2(2.0)$ & 0.6439 \\
\hline Cerebral infarction & $3(6.2)$ & $5(5.1)$ & 0.5941 \\
\hline Heart disease & $5(10.4)$ & $12(12.2)$ & 0.5783 \\
\hline Diabetes & $8(16.6)$ & $20(20.4)$ & 0.4132 \\
\hline Hyperlipidemia & $14(29.1)$ & $21(21.4)$ & 0.2291 \\
\hline \multicolumn{4}{|l|}{ Outcome } \\
\hline Recovery, n (\%) & $34(70.8)$ & $65(66.3)$ & 0.5241 \\
\hline Disability, n (\%) & $2(4.2)$ & $2(2.0)$ & \\
\hline Death, n (\%) & $12(25.0)$ & $31(31.6)$ & \\
\hline Days of illness prior to admission, $\mathrm{n}(\%)$ & $11.0(4.73)$ & $12.2(5.15)$ & 0.1717 \\
\hline \multicolumn{4}{|l|}{ Symptoms and physical findings } \\
\hline Cough, n (\%) & $33(68.8)$ & $76(78.4)$ & 0.2079 \\
\hline Fever, n $(\%)$ & $41(85.4)$ & $78(79.6)$ & 0.3944 \\
\hline Runny nose, n (\%) & $0(0)$ & $3(3.1)$ & 0.5510 \\
\hline Sputum production, $\mathrm{n}(\%)$ & $19(9.6)$ & $22(22.4)$ & $0.0305 *$ \\
\hline Myalgia/fatigue, $\mathrm{n}(\%)$ & $34(70.8)$ & $52(53.1)$ & $0.0403 *$ \\
\hline Headache, n (\%) & $4(8.3)$ & $3(3.1)$ & 0.3230 \\
\hline Diarrhea, n (\%) & $2(4.2)$ & $8(8.2)$ & 0.5827 \\
\hline Respiratory rate (breaths/min) & $20.0 \pm 1.98$ & $21.5 \pm 1.06$ & $0.0077 *$ \\
\hline Oxygen saturation (\%) & $95.0 \pm 4.81$ & $92.5 \pm 3.15$ & 0.1531 \\
\hline Heart rate (beats/min) & $97 \pm 5.76$ & $93 \pm 9.76$ & 0.2823 \\
\hline
\end{tabular}

Continuous variables with normal distribution are expressed as mean $( \pm \mathrm{SD})$ and compared using Student's $t$-test; continuous variables with non-normal distribution are expressed as median (IQR) and compared using Wilcoxon rank sum test; categorical variables are expressed as number (\%) and compared using $\chi^{2}$ test, Fisher's exact test, or Wilcoxon rank sum test. AT1RB patients on AT1R blockers, No-AT1RB patients on antihypertensive treatment other than AT1R blockers, $B M I$ body mass index.

$* \mathrm{P}<0.05$ vs. AT1R blockers 


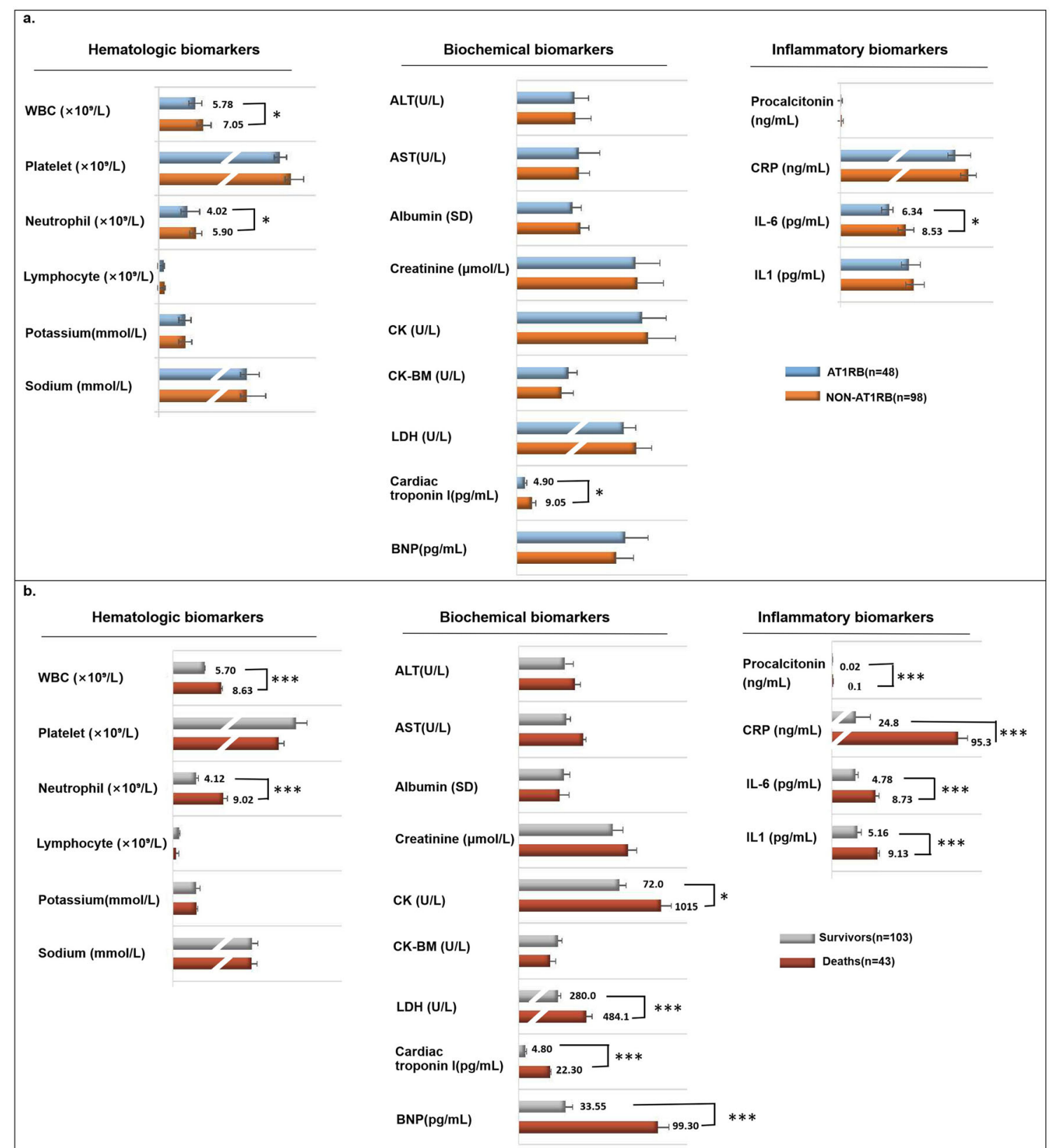

Fig. 1 Laboratory test results in hypertensive COVID-19 patients with or without AT1R blocker treatment (a) and surviving or non-surviving hypertensive COVID-19 patients (b). Continuous variables with normal distribution were expressed as mean (SD) and compared using Student's $t$-test;

serum levels of most of the cardiac function-related tests, including serum creatinine kinase (CK), lactate dehydrogenase $(\mathrm{LDH})$, cardiac troponin, and NT-proB-type natriuretic peptide (BNP), were higher in non-surviving than surviving hypertensive COVID-19 patients. The white blood cell and neutrophil counts and serum levels of procalcitonin, C-reactive protein (CRP), IL-6, and IL-1 were also higher on admission in non-surviving than surviving patients. By contrast, platelet and lymphocyte counts were higher in the surviving than nonsurviving group. Therefore, we presume that cardiac categorical variables were expressed as number (\%) and compared using $\chi^{2}$ test or Fisher's exact test. AT1RB = patients on AT1R blockers; Non-AT1RB $=$ patents on antihypertensive treatment other than AT1R blockers. $* \mathrm{P}<0.01$ vs. AT1RB group; *** $\mathrm{P}<0.0001$ vs. survivor group

dysfunction and inflammation may be the main causes of death in COVID-19 patients with hypertension (Fig. 1b).

\section{Hypertensive hACE2 Mice Have an Increased Risk for SARS-CoV-2 Infection}

To assess whether high blood pressure and organ dysfunction contribute to the increased risk for SARS-CoV-2 infection, hACE2 transgenic mice were induced hypertensive by high salt feeding $(1 \% \mathrm{NaCl})$ and subcutaneous infusion of 
angiotensin II (Ang II, $500 \mathrm{ng} / \mathrm{mg} /$ day), via osmotic minipumps, for 3 weeks before SARS-CoV-2 infection. The lungs, kidneys, and hearts were harvested at 5 dpi (Fig. 2a). Control hACE2 transgenic mice (black line) were normotensive group. By contrast, Ang II-infusion in hACE2 transgenic mice (blue line) caused a progressive increase in systolic blood pressure from an initial value of $105 \pm$ 4.1 to $178 \pm 8.3 \mathrm{~mm} \mathrm{Hg}, 3$ weeks (0d)(Fig. 2b). At 5 dpi, no viral load was detected in the kidney, but the viral load was higher in the lungs of hACE2 hypertensive transgenic mice than in the normotensive hACE transgenic mice (control)(Fig. 2c). Relative to the normotensive hACE transgenic mice (control), the expression of ACE2 was increased in three organs (lung, kidney, and heart) of hypertensive hACE2 mice (Fig. 2d), which may increase the risk for SARS-CoV-2 infection.

\section{AT1R Blocker Treatment Protects Hypertensive hACE2 Transgenic Mice From SARS-CoV-2-Mediated Organ Injury}

To investigate the effect of AT1R blocker on tissue injury post SARS-CoV-2 infection in hypertensive mice, the morphology and histopathology of the lung, heart, and kidney were evaluated at 5 dpi. There was pulmonary edema with bleeding in hypertensive hACE2 transgenic mice, which was not detected in the AT1R blocker-treated hypertensive hACE2 transgenic mice (Fig. 2e). The lung morphology was similar to the non-
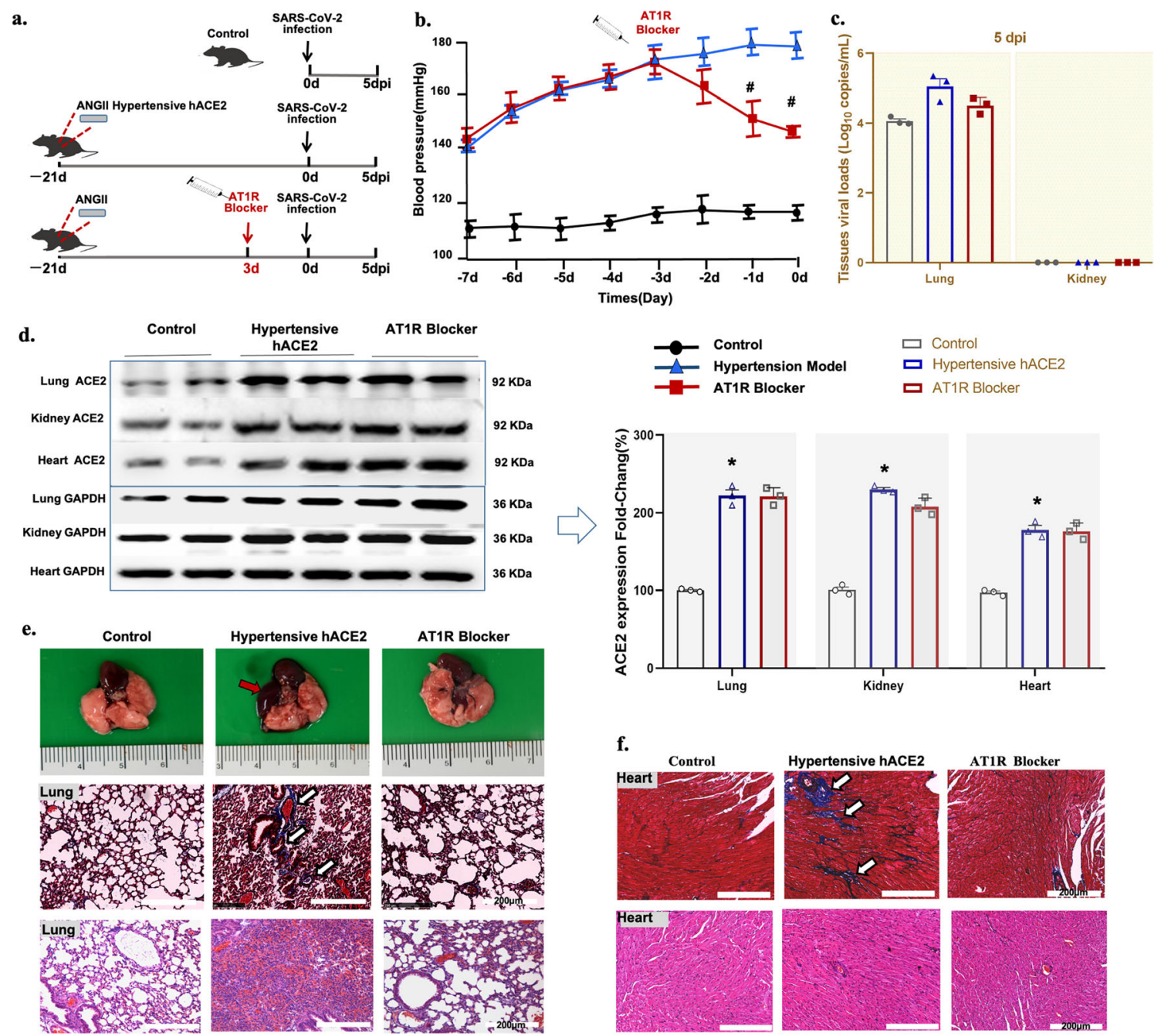

Fig. 2 Virus replication and representative histopathology in SARSCoV-2-infected hACE2 transgenic mice with hypertension induced by Ang II. a Protocol for SARS-CoV-2-infection in vivo. b Systolic blood pressure (SBP) was measured by tail-cuff plethysmography in conscious mouse, three times at 8:30 AM. c The SARS-CoV-2 load at 5 dpi. The SARS-CoV-2 loads in the lung and kidney of the mice were quantified by qRT-PCR. dAngiotensin-converting enzyme 2 (ACE2) expression quantified by western blot and analyzed by ImageJ ( $n=3 /$ group). Data are

presented as mean $\pm \mathrm{SD}$. e Morphology image (top), Massonstained(middle) and H\&E-stained(bottom) sections of the lung (scale bar is $200 \mu \mathrm{m}$ ) and heart (f) from control (normotensive hACE2 transgenic mice) and hypertensive hACE2 transgenic mice without and with AT1R blocker treatment ( 5 dpi). $* \mathrm{P}<0.01$ vs. control (untreated normotensive hACE2 transgenic mice), ${ }^{\#} \mathrm{P}<0.05$ vs. untreated hypertensive hACE2 transgenic mice, Wilcoxon rank. Data are presented as mean \pm SD 
SARS-CoV-2-infected normotensive hACE2 transgenic group (control). Increased lung and myocardial fibrosis were observed by Masson's trichrome staining in the hypertensive hACE2 transgenic mice that was improved by AT1R blocker treatment. At $5 \mathrm{dpi}$, the lung pathology progressed into severe interstitial pneumonia, with thickened alveolar septa in the untreated hypertensive hACE2 transgenic mice with SARSCoV-2 infection (Fig. 2e). There was also some interstitial pneumonia in the control normotensive hACE2 transgenic mice, which is consistent with our previous study [22, 23]. MMP2, MMP9, and FN-1 expressions were upregulated in the lung and heart (also kidney) which induced increased fibrosis and necrosis in the hypertensive hACE2 transgenic mice (Fig. S1). Thus, AT1R blocker treatment did not aggravate the histopathological injury, but instead protected the organs from damage caused by SARS-CoV-2 in hypertensive hACE2 transgenic mice.

\section{AT1R Blocker Treatment May Increase the Risk of SARS-CoV-2 Infection in the Heart and Kidney at the Early Period of Infection}

In order to study the risk of SARS-CoV-2 infection that may be caused by AT1R blockers, hypertensive hACE2 transgenic mice were pretreated with the AT1R blocker, losartan $(6.4 \mathrm{ng} / \mathrm{kg} /$ day $)$, for 3 days, before the SARS-Cov-2 virus infection as above (Fig. 2a). AT1R blocker treatment (red line) attenuated the increase in $\mathrm{BP}(145 \pm 2.9$ vs $178 \pm 8.3 \mathrm{~mm} \mathrm{Hg}, 0 \mathrm{~d})$ induced by Ang II infusion (Fig. 2b). As shown above, the viral load at 5 dpi was higher in the lungs of the hypertensive hACE2 transgenic mice than control normotensive hACE2 transgenic mice; there was no effect of AT1R blocker on the increase in the viral load (Fig. 2c). However, there was no viral load in the kidney and heart at 5 dpi, regardless of treatment (Fig. 2c).

We then investigated the ACE2 expression and viral replication at 1,3, and 5 dpi in AT1R blocker-treated and AT1R blocker-untreated (non-Ang II-infused) normotensive hACE2 transgenic mice (Fig. S2a). Western blotting showed that ACE2 protein was increased in the lung, kidney, and heart of the AT1R blocker-pretreated group at 1 and $3 \mathrm{dpi}$, compared with the normotensive hACE2 transgenic mice. However, these differences were no longer observed at $5 \mathrm{dpi}$ (Fig. S2b). The viral load was similar in the lung of untreated and AT1R blocker-treated normotensive (non-Ang II-infused) hACE2 transgenic mice at 1, 3, and 5 dpi (Fig. S2c). However, a relatively high viral load was observed in the kidney and heart of AT1R blocker-pretreated normotensive mice at $1 \mathrm{dpi}$. No viral load was detected in the kidney and heart at $3 \mathrm{dpi}$ and 5 dpi (Fig. S2c) with or without AT1R blocker pretreatment in the normotensive hACE2 transgenic mice. These results suggest that AT1R blockade may increase the risk of SARS-CoV2 infection in the heart and kidney at the early period of infection, even in the absence of hypertension.
In normotensive hACE2 transgenic mice with SARS-CoV2 infection, there were no differences in histopathological changes in the lung, heart, and kidney at 1,3 , and 5 dpi between the AT1R blocker-untreated and pretreated group (Figs. S3 and S4).

\section{AT1R Blocker Treatment Decreases the Inflammatory Reaction in Hypertensive hACE2 Transgenic Mice with SARS-CoV-2 Infection}

The protein expressions of inflammatory markers (IL-6 and $\mathrm{TNF} \alpha$ ) were higher in the lung, kidney, and heart, of hypertensive hACE2 transgenic mice than normotensive hACE2 transgenic mice during SARS-CoV-2 infection. The increased expression of inflammatory markers in hypertensive hACE2 transgenic mice was downregulated by AT1R blocker treatment (Fig. 3a and b). The mRNA expressions of two inflammatory factors (IL-6 and TNF $\alpha$ ) were also decreased in the lung, kidney, and heart of AT1R blocker-treated hypertensive hACE2 transgenic mice (Fig. 3c). These results indicate that AT1R blocker treatment decreases the inflammatory reaction in hypertensive hACE2 transgenic mice with SARS-CoV-2 infection, which may justify its use in hypertensive patients infected with SARS-CoV-2.

\section{AT1R Blocker Treatment Protects Hypertensive hACE2 Transgenic Mice from Cardiac Injury by Ameliorating Ang II/Ang1-7 Imbalance}

We have found that cardiac dysfunction may be the main cause of death in COVID-19 patients with hypertension [24]. Epidemiological studies also indicated that COVID-19 is more severe in patients with hypertension, coronary heart disease, and diabetes [25]. ACE2-processed Ang-(1-7)-Mas$\mathrm{R}$ axis leads to antihypertensive and cardioprotective effects (Fig. 3d). MasR, the Ang 1-7 receptor, was upregulated in the lung, kidney, and heart of hypertensive hACE transgenic mice with SARS-CoV-2 infection. The expression of MasR in the heart was further increased in hypertensive hACE transgenic mice treated with AT1R blocker; AT1R blocker treatment did not change MasR expression in the lung and kidney (Fig. 3e). Liu et al reported that Ang II levels in COVID-19 patients correlated with viral load and organ injury [26]. We also found increased serum Ang II levels in hypertensive hACE2 transgenic mice, which were decreased by AT1R blocker treatment although the levels were still higher than the untreated hypertensive hACE2 transgenic mice (Fig. 3f). Serum Ang 1-7 levels were also increased in the hypertensive hACE2 transgenic mice, but AT1R blocker treatment further increased the serum Ang 1-7 levels, the opposite of that found with Ang II (Fig. 3f).

We also found that the serum levels of cardiac injury markers, such as cardiac troponin I (cTnI) and creatine 

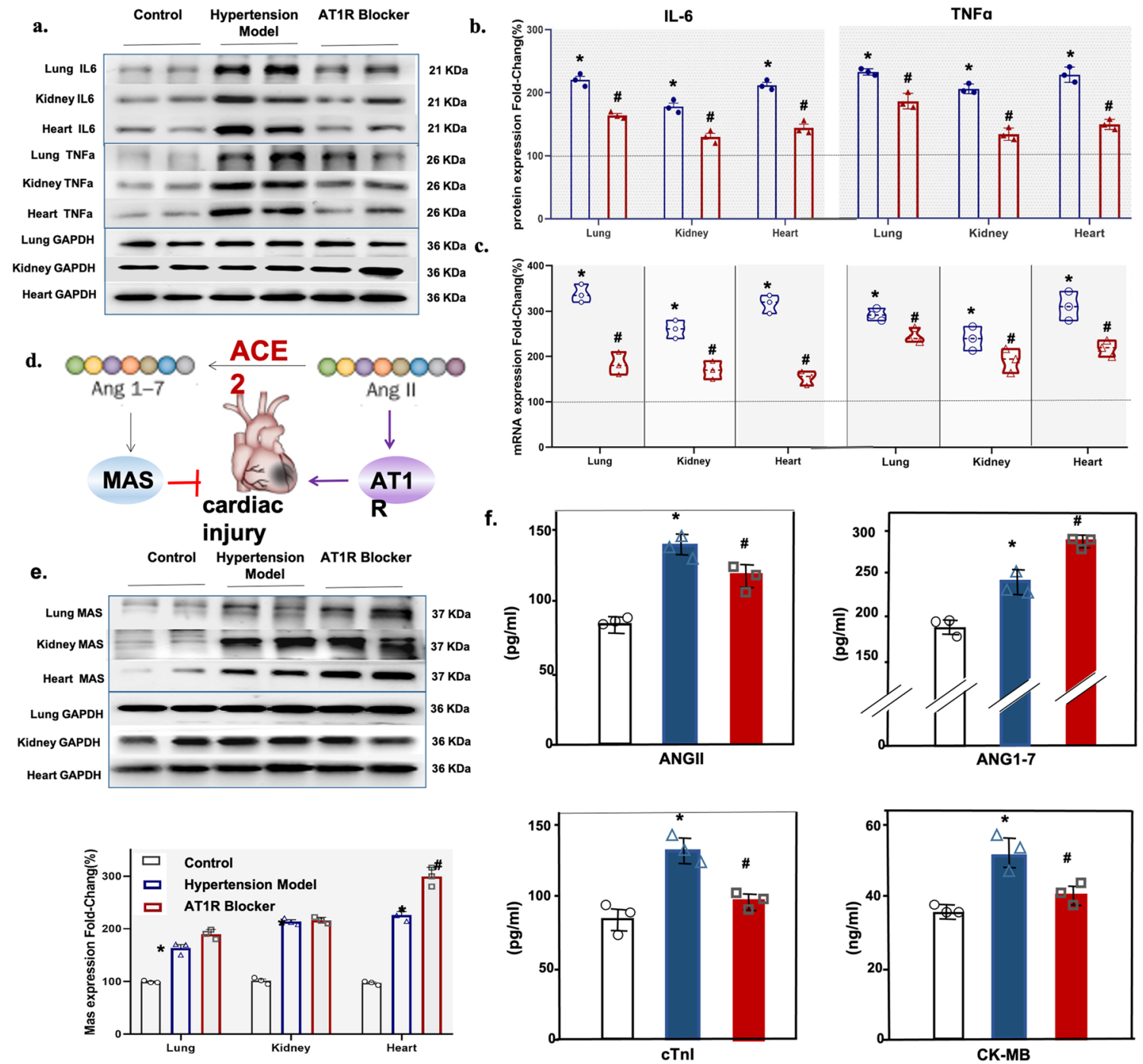

Fig. 3 Inflammation and cardiac function markers in SARS-CoV-2infected normotensive and hypertensive hACE2 transgenic mice with or without AT1R blocker treatment. a, b Western blots of inflammation markers, IL- 6 and TNF $\alpha$, analyzed by ImageJ. $\mathbf{c}$ mRNA expression of inflammation markers quantified by qRT-PCR in control (normotensive hACE2 transgenic mice) and hypertensive hACE2 transgenic mice without and with AT1R blocker treatment. d Ang II/Ang1-7 imbalance as a key player in cardiac injury. e Western blots of cardiac MasR and

kinase-myocardial band (CK-MB), were increased in SARSCoV-2-infected hypertensive hACE2 transgenic mice but normalized after AT1R blocker treatment (Fig. 3f), which is consistent with the results in our patient study (see above). These results indicate that AT1R blocker may protect hypertensive hACE2 mice from cardiac injury by stimulating the Ang-(17)-Mas-R axis and inhibiting the Ang II axis.

\section{Discussion}

The SARS-CoV-2 uses ACE2 as a co-receptor to gain entry inside human cells, where ACE2 is highly expressed, such as
GAPDH analyzed by ImageJ; f serum levels of Ang II, Ang 1-7, cardiac troponin I (cTnI), and creatine kinase-MB(CK-MB) in control normotensive hACE transgenic mice and hypertensive hACE2 transgenic mice without or with AT1R blocker treatment ( $\mathrm{n}=3$ /group, ${ }^{*} \mathrm{P}<0.01$ vs. control, $\# \mathrm{P}<0.05$ vs. untreated hypertensive hACE2 transgenic mice), Wilcoxon rank. Immunoblots (a and $\mathbf{e}$ ) are representatives of three independent experiments.

the lung, heart, intestine, and kidney, among others [3-5]. SARS-CoV-2 could exploit species-specific interferon-driven upregulation of ACE2 to enhance infection [27]. In the current study, we found that SARS-CoV-2 viral load in the heart and kidney of normotensive hACE2 transgenic mice was increased by AT1R blocker treatment at $1 \mathrm{dpi}$. The highest SARS-CoV-2 viral load was in the lung of normotensive and hypertensive hACE2 transgenic mice, which was not affected by AT1R blocker treatment. However, the SARS-CoV2 loading did not increase the severity of injury in the lung, heart, and kidney of normotensive hACE2 transgenic mice with AT1R blocker pretreatment (Supplemental Fig. S3). By contrast, in hypertensive hACE2 transgenic mice, the AT1R 
blocker treatment was protective against tissue injury and inflammation in the lung, kidney, and heart. ACE2 is critical for early tissue tolerance responses to respiratory infection because elevated ACE2 may increase the ability of the host to tolerate tissue damage $[28,29]$. However, while the amount of SARS-CoV-2 load has been reported to predict mortality [30], an effect of AT1R blockers on the relationship between viral load and mortality has not been reported.

In the current study, all hypertensive COVID-19 patients in 15 departments of the hospital during the local epidemic period were investigated to study the severity of SARS-CoV-2 infection in hypertensive COVID-19 patients with or without AT1R blocker treatment. It is very difficult to determine if AT1R blockers affect the severity of SARS-CoV-2 infection in human epidemiological investigation because the time of human contact with the virus is unknown, even though one can compare the number of COVID-19 cases, with or without AT1R blocker treatment, in the population in a specific area. Thus, with a human survey, one can only evaluate the effect of AT1 blocker on the outcome or the severity of SARS-CoV-2 infection. All of the hypertensive COVID-19 patients in our study stopped taking AT1R blockers after admission to the hospital. The intake of AT1R blockers, with the average of 11 days from the onset of illness to the hospital admission of hypertensive COVID-19 patients, suggests that AT1R blockers decreased the severity of SARSCoV-2 infection. Renin-angiotensin system (RAS) inhibitors have been reported to improve the clinical outcome of COVID-19 patients with hypertension [31]. However, other investigators have reported that neither ACE inhibitors nor AT1R blockers affected the risk of mild-to-moderate or severe COVID-19 disease [32, 33]. In our study, the clinical severity and number of symptoms were less in the AT1R blocker-treated than non-AT1R blocker-treated hypertensive COVID-19 patients. There may be also more recovery and less death in COVID-19 hypertensive patients treated with AT1R blockers. The main causes of death in COVID-19 patients were acute kidney injury, multi-organ failure, inflammatory storm, and thromboinflammation [34-39]. Therefore, the laboratory tests on admission could be added to the clinical presentation to determine the effect of ACE inhibitors or AT1R blockers on the severity of SARS-CoV-2 infection.

Acute myocarditis, with elevated blood high-sensitivity troponin T and CK-MB levels, was reported to be associated with the severity of COVID-19, without symptoms and signs of interstitial pneumonia [40]. We also found that the lesser symptoms in COVID-19 patients treated with AT1R blockers were associated with lower serum cTnI levels in hypertensive COVID-19 patients treated with AT1R blockers than those not taking them. The serum cTnI and other cardiac biomarkers were higher in non-survivors than survivors. A meta-analysis study reported that cTnI values were higher in patients with severe than those with milder COVID-19 [41]. Cardiac troponins, i.e., cTnI, are the biomarkers of choice in the diagnosis of acute myocardial infarction in patients in the emergency room [42]. In hACE transgenic mice, the serum levels of cardiac injury markers (cTnI and CK-MB) were higher in hypertensive than normotensive hACE2 mice, which were normalized by AT1R blocker treatment. Therefore, AT1R blockers may decrease the severity of myocardial injury in hypertensive COVID-19 patients.

The protective effect of AT1R blockers in hypertensive COVID-19 patients has been reviewed recently [12, 43-45]. As aforementioned, SARS-CoV-2 uses ACE2 to enter the cell $[5,17,46]$. An imbalance in the RAS that favors the Ang II/ AT1R axis increases the likelihood of developing severe COVID-19 [46-49]. ACE2 converts Ang II to angiotensin 1-7 (Ang1-7). An increase in ACE2 expression may protect the organs from the virus injury by increasing Ang-(1-7) and decreasing Ang II levels [49, 50]. Ang1-7 binds to the Mas receptor (MasR) that mediates anti-inflammatory, antioxidative, and vasodilatory effects $[49,50]$. In hypertensive hACE2 transgenic mice, serum Ang1-7 levels and cardiac MasR expressions were increased, but serum Ang II levels were decreased in AT1R blocker group. We also found that serum Ang-(1-7) levels at 1 dpi were increased in SARS-CoV-2infected hACE2 transgenic mice with AT1R blocker pretreatment compared with AT1R blocker-untreated mice (data not shown). Therefore, we suggest that AT1R blocker may protect hypertensive COVID-19 patients from heart injury caused by SARS-CoV-2 infection via the ACE2-Ang-(1-7)-Mas-R axis (Scheme 1).

\section{Perspectives}

The clinical severity of SARS-CoV-2 infection was lesser in AT1R blocker-treated than AT1R blocker-untreated hypertensive patients. AT1R blockers were protective against organ injury in hypertensive hACE2 transgenic mice. AT1R blocker treatment was also associated with a decrease in inflammatory markers (TNF $\alpha$ and IL-6). Serum cTnI may be a biomarker that predicts the progression of COVID-19. Although AT1R blockers may increase the risk of SARS-CoV-2 infection in the heart and kidney at the early period of infection, they may be beneficial in the treatment of hypertensive patients with SARS-CoV-2 infection. However, studies in large populations are still needed to evaluate the effect and mechanism of AT1R blockade on the severity and outcome of COVID19 patients with cardiovascular diseases. More studies are also needed to determine the mechanism of the beneficial effect of AT1R blockers, in general, or specific AT1R blockers, in particular, in hypertensive animal models. 
Scheme 1 Processing and function scheme of AT1R blocker action in hypertensive COVID-19 patients. Angiotensin II type I receptor (AT1R) blocker increases angiotensin-converting enzyme 2 (ACE2) expression. The increased ACE2 expression may potentiate the risk of SARS-CoV2 infection, which results in cardiac injury. However, the increase in ACE2 converts more angiotensin (Ang) II to Ang-(1-7), which binds to the Mas receptor (Mas-R) to protect the heart from injury caused by SARS-CoV-2 infection. AT1R blockade also stimulates plasm angiotensin II levels but decreases renal angiotensin II levels [51]

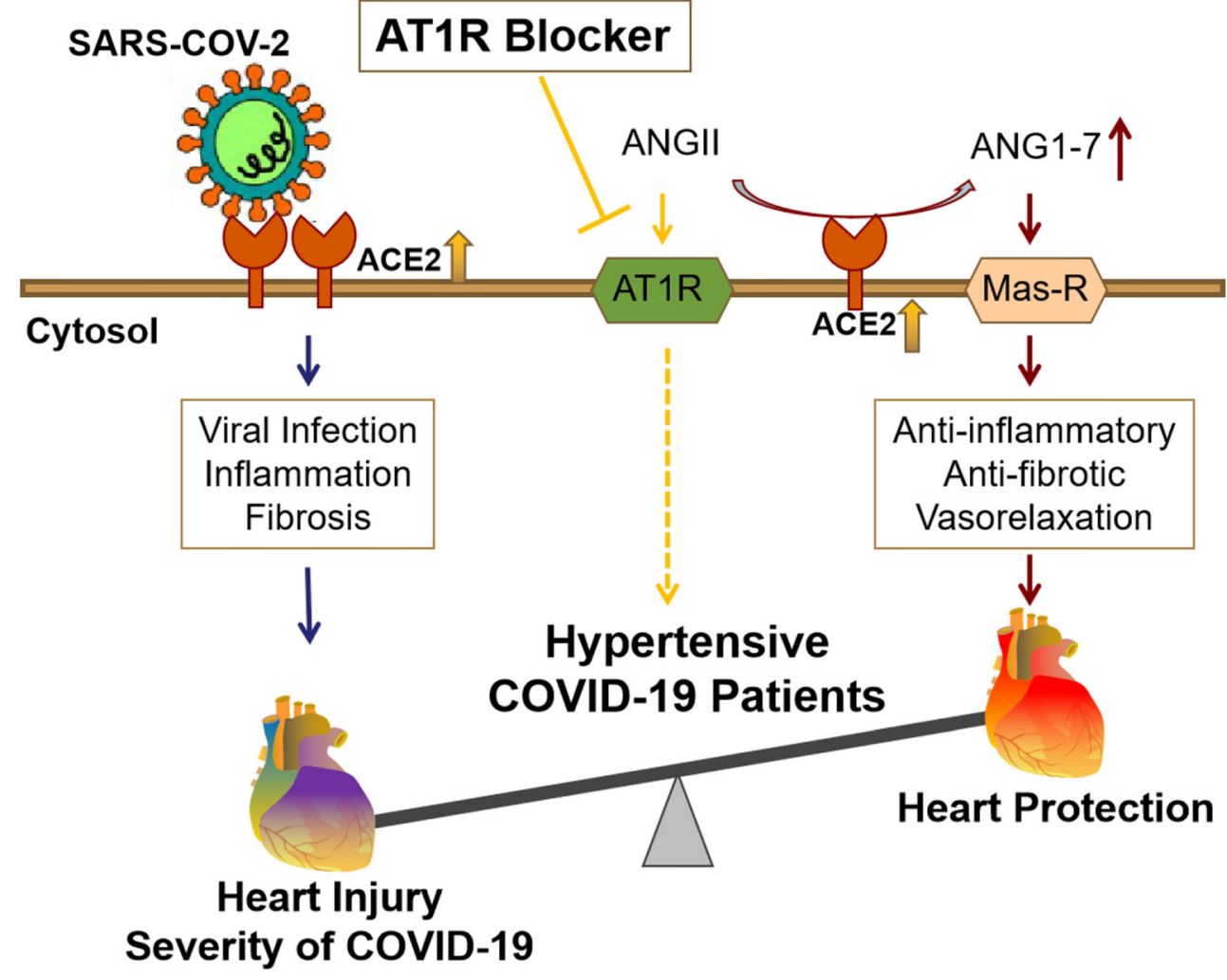

\section{Limitations}

Our study has some limitations. First, this study had to be done in the animal biosafety level 3 (ABSL3) facility, where ultrasound and telemetric measurement of blood pressure are not available. Therefore, we cannot provide cardiac ultrasound data and only tested several serum markers to represent cardiac function. Second, although our study provides additional evidence that ACE2/Ang-1-7/MasR is the protective arm of the RAS, which may countervail the deleterious effects of Ang II in several organs, the mechanisms were not determined. Finally, these studies in Wuhan Chinese may not be generalizable to other racial/ethnic groups.

Supplementary Information The online version contains supplementary material available at https://doi.org/10.1007/s12265-021-10147-3.

Author Contribution The authors' contribution: X.J. performed the experiments and wrote the animal study section; D.L. collected the clinical data; Y.L. participated in the project design; L.B. helped perform the animal experiments; L.Z. analyzed the patient samples; H.G. performed the quality testing; W.D. studied the SARS-CoV-2 load; J.X. analyzed the animal data; J.L. helped perform the animal experiments; X.L. performed the animal surgery; L.L. performed the SARS-CoV-2 infection; J.W. coperformed the SARS-CoV-2 infection; X.Y. bred the animals; S.W. helped in clinical data collection; M.Y. helped in the clinical data collection; W.L. analyzed the clinical data; P.A.J. reviewed and edited the manuscript; D.Z. reviewed the manuscript; Z.Y. was responsible for the overall project design and manuscript review; C.Q. helped in the project design and funding support.
Funding These studies were supported, in part, by grants from the Chinese Academy of Medical Sciences Innovation Fund for Medical Sciences (CIFMS, 2021-1-I2M-035, 2016-I2M-1-016, 2019-I2M-1001, 2016-I2M-2-006), National Mega projects of China for Major Infectious Diseases (2017ZX10304402), National Key Research and Development Project of China (Grant No. 2016YFD0500304), and US National Institutes of Health (DK039308, DK119652, and HL074940).

\section{Declarations}

Ethics Approval The human subject study was approved by the Research Ethics Commission of Jin Yin-Tan Hospital (No.KY-202054.01), and the requirement for informed consent was waived by the Ethics Commission of the designated hospital for emerging infectious diseases. Regarding the animal experiments, all the procedures were approved by the Animal Care and Use Committee of the Institute of Laboratory Animal Science, Peking Union Medical College (BLL20001). (See the supporting information for details)

Conflict of Interest The authors declare no competing interests.

Open Access This article is licensed under a Creative Commons Attribution 4.0 International License, which permits use, sharing, adaptation, distribution and reproduction in any medium or format, as long as you give appropriate credit to the original author(s) and the source, provide a link to the Creative Commons licence, and indicate if changes were made. The images or other third party material in this article are included in the article's Creative Commons licence, unless indicated otherwise in a credit line to the material. If material is not included in the article's Creative Commons licence and your intended use is not permitted by statutory regulation or exceeds the permitted use, you will need to obtain permission directly from the copyright holder. To view a copy of this licence, visit http://creativecommons.org/licenses/by/4.0/. 


\section{References}

1. Huang, C., Wang, Y., Li, X., Ren, L., Zhao, J., Hu, Y., Zhang, L., Fan, G., Xu, J., Gu, X., et al. (2020). Clinical features of patients infected with 2019 novel coronavirus in Wuhan China. Lancet, 395, 497-506. https://doi.org/10.1016/S0140-6736(20)30183-5.

2. Wu, Z., \& McGoogan, J. M. (2020). Characteristics of and important lessons from the coronavirus disease 2019 (COVID-19) outbreak in China: Summary of a report of 72314 cases from the Chinese Center for Disease Control and Prevention. JAMA, 323, 1239-1242. https://doi.org/10.1001/jama.2020.2648.

3. Tian, X., Li, C., Huang, A., Xia, S., Lu, S., Shi, Z., Lu, L., Jiang, S., Yang, Z., Wu, Y., et al. (2020). Potent binding of 2019 novel coronavirus spike protein by a SARS coronavirus-specific human monoclonal antibody. Emerg Microbes Infect, 9, 382-385. https:// doi.org/10.1080/22221751.2020.1729069.

4. Zhou, P., Yang, X. L., Wang, X. G., Hu, B., Zhang, L., Zhang, W., Si, H. R., Zhu, Y., Li, B., \& Huang, C. L. (2020). A pneumonia outbreak associated with a new coronavirus of probable bat origin. Nature, 579, 270-273. https://doi.org/10.1038/s41586-020-2012-7.

5. Chen, Y., Guo, Y., Pan, Y., \& Zhao, Z. J. (2020). Structure analysis of the receptor binding of 2019-nCoV. Biochem Biophys Res Commun, 525, 135-140. https://doi.org/10.1016/j.bbrc.2020.02.071.

6. Smyth, L. J., Canadas-Garre, M., Cappa, R. C., Maxwell, A. P., \& McKnight, A. J. (2019). Genetic associations between genes in the renin-angiotensin-aldosterone system and renal disease: A systematic review and meta-analysis. BMJ Open, 9, e026777. https://doi. org/10.1136/bmjopen-2018-026777.

7. Mehta, P. K., \& Griendling, K. K. (2007). Angiotensin II cell signaling: Physiological and pathological effects in the cardiovascular system. Am J Physiol Cell Physiol, 292, C82-C97. https://doi.org/ 10.1152/ajpcell.00287.2006.

8. Santos, R. A. S., Sampaio, W. O., Alzamora, A. C., Motta-Santos, D., Alenina, N., Bader, M., \& Campagnole-Santos, M. J. (2018). The ACE2/Angiotensin-(1-7)/MAS axis of the renin-angiotensin system: Focus on angiotensin-(1-7). Physiol Rev, 98, 505-553. https://doi.org/10.1152/physrev.00023.2016.

9. Furuhashi, M., Moniwa, N., Mita, T., Fuseya, T., Ishimura, S., Ohno, K., Shibata, S., Tanaka, M., Watanabe, Y., Akasaka, H., et al. (2015). Urinary angiotensin-converting enzyme 2 in hypertensive patients may be increased by olmesartan, an angiotensin II receptor blocker. Am J Hypertens, 28, 15-21. https://doi.org/10. 1093/ajh/hpu086.

10. Wang, X., Ye, Y., Gong, H., Wu, J., Yuan, J., Wang, S., Yin, P., Ding, Z., Kang, L., Jiang, Q., et al. (2016). The effects of different angiotensin II type 1 receptor $b$ lockers on the regulation of the ACE-AngII-AT1 and ACE2-Ang (1-7)-Mas axes in pressure overload-induced cardiac remodeling in male mice. J Mol Cell Cardiol, 97, 180-190. https://doi. org/10.1016/j.yjmcc.2016.05.012.

11. Ishiyama, Y., Gallagher, P. E., Averill, D. B., Tallant, E. A., Brosnihan, K. B., \& Ferrario, C. M. (2004). Upregulation of angiotensin-converting enzyme 2 after myocardial infarction by blockade of angiotensin II receptors. Hypertension, 43, 970-976. https://doi.org/10.1161/01.HYP.0000124667.34652.1a.

12. Gurwitz, D. (2020). Angiotensin receptor blockers as tentative SARS-CoV-2 therapeutics. Drug Dev Res, 81, 537-540. https:// doi.org/10.1002/ddr.21656.

13. Zhou, F., Liu, Y. M., Xie, J., Li, H., Lei, F., Yang, H., Qin, J. J., Cai, J., Zhang, X. J., Wu, B., et al. (2020). Comparative impacts of ACE inhibitors versus angiotensin II receptor blockers on the risk of COVID-19 mortality. Hypertension, 76, e15-e17. https://doi.org/ 10.1161/HYPERTENSIONAHA.120.15622.

14. Hippisley-Cox J, Young D, Coupland C, Channon KM, Tan PS, Harrison DA, Rowan K, Aveyard P, Pavord ID, Watkinson PJ (2020). Risk of severe COVID-19 disease with ACE inhibitors and angiotensin receptor blockers: cohort study including 8.3 million people. Heart. 317-393. https://doi.org/10.1136/heartjnl-2020-317393

15. Devaux, C. A., Rolain, J. M., \& Raoult, D. (2020). ACE2 receptor polymorphism: Susceptibility to SARS-CoV-2, hypertension, multiorgan failure, and COVID-19 disease outcome. J Microbiol Immunol Infect, 53, 425-435. https://doi.org/10.1016/j.jmii.2020.04.015.

16. Fang, L., Karakiulakis, G., \& Roth, M. (2020). Are patients with hypertension and diabetes mellitus at increased risk for COVID-19 infection? Lancet Respir Med, 8, e21. https://doi.org/10.1016/ S2213-2600(20)30116-8.

17. Wang, K., Gheblawi, M., \& Oudit, G. Y. (2020). Angiotensin converting enzyme 2: A double-edged sword. Circulation, 142, 426-428. https://doi.org/10.1161/CIRCULATIONAHA.120. 047049.

18. Bao, L., Deng, W., Huang, B., Gao, H., Liu, J., Ren, L., Wei, Q., Yu, P., Xu, Y., Qi, F., et al. (2020). The pathogenicity of SARSCoV-2 in hACE2 transgenic mice. Nature, 583, 830-833. https:// doi.org/10.1038/s41586-020-2312-y.

19. Dinnon, K. H., Leist, S. R., Schafer, A., Edwards, C. E., Martinez, D. R., Montgomery, S. A., West, A., Yount, B. L., Hou, Y. J., Adams, L. E., et al. (2020). A mouse-adaptedSARS-CoV-2 model for the evaluation of COVID-19 medical countermeasures. Nature, 586, 560-566. https://doi.org/10.1038/s41586-020-2708-8.

20. Iaccarino, G., Grassi, G., Borghi, C., Ferri, C., Salvetti, M., Volpe, M., $\&$ SARS-RAS Investigators. (2020). Age and multimorbidity predict death among COVID-19 patients: Results of the SARS-RAS study of the Italian Society of Hypertension. Hypertension, 76, 366-372. https:// doi.org/10.1161/HYPERTENSIONAHA.120.15324.

21. Lutz, C., Maher, L., Lee, C., \& Kang, W. (2020). COVID-19 preclinical models: Human angiotensin-converting enzyme 2 transgenic mice. Hum Genomics, 14, 20. https://doi.org/10.1186/s40246020-00272-6.

22. Yang, X. H., Deng, W., Tong, Z., Liu, Y. X., Zhang, L. F., Zhu, H., Gao, H., Huang, L., Liu, Y. L., Ma, C. M., et al. (2007). Mice transgenic for human angiotensin-converting enzyme 2 provide a model for SARS coronavirus infection. Comp Med, 57, 450-459.

23. Cao, Y., Su, B., Guo, X., Sun, W., Deng, Y., Bao, L., Zhu, Q., Zhang, X., Zheng, Y., Geng, C., et al. (2020). Potent neutralizing antibodies against SARS-CoV-2 identified by high-throughput single-cell sequencing of convalescent patients' B cells. Cell, 182, 7384. https://doi.org/10.1016/j.cell.2020.05.025.

24. Chen, T., Wu, D., Chen, H., Yan, W., Yang, D., Chen, G., Ma, K., $\mathrm{Xu}, \mathrm{D} ., \mathrm{Yu}, \mathrm{H}$., Wang, H., et al. (2019). Clinical characteristics of 113 deceased patients with coronavirus disease 2019: Retrospective study. BMJ, 368, m1091. https://doi.org/10.1136/bmj.m1091.

25. Guan, W. J., Ni, Z. Y., Hu, Y., Liang, W. H., Ou, C. Q., He, J. X., Liu, L., Shan, H., Lei, C. L., Hui, D. S. C., et al. (2019). China Medical Treatment Expert Group. Clinical Characteristics of Coronavirus Disease 2019 in China. N Engl J Med, 382, 17081720. https://doi.org/10.1056/NEJMoa2002032.

26. Liu, Y., Yang, Y., Zhang, C., Huang, F., Wang, F., Yuan, J., Wang, Z., Li, J., Li, J., Feng, C., et al. (2020). Clinical and biochemical indexes from 2019-nCoV infected patients linked to viral loads and lung injury. Sci China Life Sci, 63, 364-374. https://doi.org/10. 1007/s11427-020-1643-8.

27. Ziegler, C. G. K., Allon, S. J., Nyquist, S. K., Mbano, I. M., Miao, V. N., Tzouanas, C. N., Cao, Y., Yousif, A. S., Bals, J., Hauser, B. M., et al. (2020). SARS-CoV-2 receptor ACE2 is an interferonstimulated gene in human airway epithelial cells and is detected in specific cell subsets across tissues. Cell, 181, 1016-1035. https:// doi.org/10.1016/j.cell.2020.04.035.

28. Ferreri, A. J., Illerhaus, G., Zucca, E., \& Cavalli, F. (2010). Flows and flaws in primary central nervous system lymphoma. Nat Rev Clin Oncol, 7, 1038-1042. https://doi.org/10.1038/nrclinonc.2010.9-c1.

29. Zou, Z., Yan, Y., Shu, Y., Gao, R., Sun, Y., Li, X., Ju, X., Liang, Z., Liu, Q., Zhao, Y., et al. (2014). Angiotensin-converting enzyme 2 
protects from lethal avian influenza A H5N1 infections. Nat Commun, 5, 3594. https://doi.org/10.1038/ncomms4594.

30. Pujadas, E., Chaudhry, F., McBride, R., Richter, F., Zhao, S., Wajnberg, A., Nadkarni, G., Glicksberg, B. S., Houldsworth, J., \& Cordon-Cardo, C. (2020). SARS-CoV-2 viral load predicts COVID-19 mortality. Lancet Respir Med, 8, e70. https://doi.org/ 10.1016/S2213-2600(20)30354-4.

31. Meng, J., Xiao, G., Zhang, J., He, X., Ou, M., Bi, J., Yang, R., Di, W., Wang, Z., Li, Z., et al. (2020). Renin-angiotensin system inhibitors improve the clinical outcomes of COVID-19 patients with hypertension. Emerg Microbes Infect, 9, 757-760. https://doi.org/ 10.1080/22221751.2020.1746200.

32. Reynolds, H. R., Adhikari, S., Pulgarin, C., Troxel, A. B., Iturrate, E., Johnson, S. B., Hausvater, A., Newman, J. D., Berger, J. S., Bangalore, S., et al. (2020). Renin-angiotensin-aldosterone system inhibitors and risk of Covid-19. N Engl J Med, 382, 2441-2448. https://doi.org/10.1056/NEJMoa2008975.

33. Mancia, G., Rea, F., Ludergnani, M., Apolone, G., \& Corrao, G. (2020). Renin-angiotensin-aldosterone system blockers and the risk of Covid-19. N Engl J Med, 382, 2431-2440. https://doi.org/10. 1056/NEJMoa2006923.

34. Cheng, Y., Luo, R., Wang, K., Zhang, M., Wang, Z., Dong, L., Li, J., Yao, Y., Ge, S., \& Xu, G. (2020). Kidney disease is associated with in-hospital death of patients with COVID-19. Kidney Int, 97, 829-838. https://doi.org/10.1016/j.kint.2020.03.005.

35. Ronco, C., Reis, T., \& Husain-Syed, F. (2020). Management of acute kidney injury in patients with COVID-19. Lancet Respir Med, 8, 738-742. https://doi.org/10.1016/S2213-2600(20)30229-0.

36. Devaux, C. A., Rolain, J. M., \& Raoult, D. (2020). ACE2 receptor polymorphism: Susceptibility to SARS-CoV-2, hypertension, multi-organ failure, and COVID-19 disease outcome. J Microbiol Immunol Infect., 53, 425-435. https://doi.org/10.1016/j.jmii.2020. 04.015.

37. Xu, X., Han, M., Li, T., Sun, W., Wang, D., Fu, B., Zhou, Y., Zheng, X., Yang, Y., Li, X., et al. (2020). Effective treatment of severe COVID-19 patients with tocilizumab. Proc Natl Acad Sci U $S$ A, 117, 10970-10975. https://doi.org/10.1073/pnas.2005615117.

38. Henderson, L. A., Canna, S. W., Schulert, G. S., Volpi, S., Lee, P. Y., Kernan, K. F., Caricchio, R., Mahmud, S., Hazen, M. M., Halyabar, O., et al. (2020). On the alert for cytokine storm: Immunopathology in COVID-19. Arthritis Rheumatol, 272, 1059-1063. https://doi.org/10.1002/art.41285.

39. Chaudhary R, Garg J, Houghton DE, Murad MH, Kondur A, Chaudhary R, Wysokinski WE, McBane RD 2nd Thromboinflammatory biomarkers in COVID-19: Systematic review and meta-analysis of 17,052 patients. Mayo Clin Proc Innov Qual Outcomes. 2021. https://doi.org/10.1016/j.mayocpiqo.2021.01. 009. Online ahead of print.

40. Inciardi, R. M., Lupi, L., Zaccone, G., Italia, L., Raffo, M., Tomasoni, D., Cani, D. S., Cerini, M., Farina, D., Gavazzi, E., et al. (2020). Cardiac involvement in a patient with coronavirus disease 2019 (COVID-19). JAMA Cardiol, 5, 1-6. https://doi.org/ 10.1001/jamacardio.2020.
41. Lippi, G., Lavie, C. J., \& Sanchis-Gomar, F. (2020). Cardiac troponin I in patients with coronavirus disease 2019 (COVID-19): Evidence from a meta-analysis. Prog Cardiovasc Dis, 63, 390391. https://doi.org/10.1016/j.pcad.2020.03.001.

42. Westermann, D., Neumann, J. T., Sorensen, N. A., \& Collinson, P. O. (2017). High-sensitivity assays for troponin in patients with cardiac disease. Nat Rev Cardiol, 14, 472-483. https://doi.org/10. 1038/nrcardio.2017.48

43. Kreutz, R., Algharably, E. A. E., Azizi, M., Dobrowolski, P., Guzik, T., Januszewicz, A., Persu, A., Prejbisz, A., Riemer, T. G., Wang, J. G., et al. (2020). Hypertension, the renin-angiotensin system, and the risk of lower respiratory tract infections and lung injury: Implications for COVID-19. Cardiovasc Res, 116, 16881699. https://doi.org/10.1093/cvr/cvaa097.

44. South, A. M., Diz, D. I., \& Chappell, M. C. (2020). COVID-19, ACE2, and the cardiovascular consequences. Am J Physiol Heart Circ Physiol, 318, H1084-H1090. https://doi.org/10.1152/ajpheart. 00217.2020

45. Danser, A. H. J., Epstein, M., \& Batlle, D. (2020). Reninangiotensin system blockers and the COVID-19 pandemic: At present there is no evidence to abandon renin-angiotensin system blockers. Hypertension, 75, 1382-1385. https://doi.org/10.1161/ HYPERTENSIONAHA.120.15082.

46. Wahba, L., Jain, N., Fire, A. Z., Shoura, M. J., Artiles, K. L., McCoy, M. J., \& Jeong, D. E. (2020). An extensive metametagenomic search identifies SARS-CoV-2-homologous sequences in pangolin lung viromes. mSphere, 5, e00160-e00120. https://doi.org/10.1128/mSphere.00160-20.

47. Henry, B. M., \& Vikse, J. (2020). Clinical characteristics of Covid19 in China. $N$ Engl J Med, 382, 1860-1861. https://doi.org/10. 1056/NEJMc2005203.

48. Sanchis-Gomar, F., Lavie, C. J., Perez-Quilis, C., Henry, B. M., \& Lippi, G. (2020). Angiotensin-converting enzyme 2 and antihypertensives (angiotensin receptor blockers and angiotensin-converting enzyme inhibitors) in coronavirus disease 2019. Mayo Clin Proc, 95, 1222-1230. https://doi.org/10.1016/j.mayocp.2020.03.026.

49. Simoes, E., Silva, A. C., \& Teixeira, M. M. (2016). ACE inhibition, ACE2 and angiotensin-(1-7) axis in kidney and cardiac inflammation and fibrosis. Pharmacol Res, 107, 154-162. https://doi.org/10. 1016/j.phrs.2016.03.018.

50. Santos, R. A. S., Oudit, G. Y., Verano-Braga, T., Canta, G., Steckelings, U. M., \& Bader, M. (2019). The renin-angiotensin system: Going beyond the classical paradigms. Am J Physiol Heart Circ Physiol, 316(5), H958-H970. https://doi.org/10.1152/ ajpheart.oo723.2018.

51. Kobori, H., Nangaku, M., Navar, L. G., \& Nishiyama, A. (2007). The intrarenal renin-angiotensin system: From physiology to the pathobiology of hypertension and kidney disease. Pharmacol, 59(3), 251-287. https://doi.org/10.1124/pr.59.3.3.

Publisher's Note Springer Nature remains neutral with regard to jurisdictional claims in published maps and institutional affiliations. 